\title{
Greenhouse Gas Emission Accounting and Management of Low-Carbon Community
}

\author{
Dan Song, Meirong Su, Jin Yang, and Bin Chen \\ State Key Laboratory of Water Environment Simulation, School of Environment, Beijing Normal University, Beijing 100875, China \\ Correspondence should be addressed to Bin Chen, chenb@bnu.edu.cn
}

Received 7 September 2012; Accepted 4 November 2012

Academic Editors: N. H. Afgan, Md. Hasanuzzaman, and F. Pilo

Copyright () 2012 Dan Song et al. This is an open access article distributed under the Creative Commons Attribution License, which permits unrestricted use, distribution, and reproduction in any medium, provided the original work is properly cited.

As the major source of greenhouse gas (GHG) emission, cities have been under tremendous pressure of energy conservation and emission reduction for decades. Community is the main unit of urban housing, public facilities, transportation, and other properties of city's land use. The construction of low-carbon community is an important pathway to realize carbon emission mitigation in the context of rapid urbanization. Therefore, an efficient carbon accounting framework should be proposed for $\mathrm{CO}_{2}$ emissions mitigation at a subcity level. Based on life-cycle analysis (LCA), a three-tier accounting framework for the carbon emissions of the community is put forward, including emissions from direct fossil fuel combustion, purchased energy (electricity, heat, and water), and supply chain emissions embodied in the consumption of goods. By compiling a detailed $\mathrm{CO}_{2}$ emission inventory, the magnitude of carbon emissions and the mitigation potential in a typical high-quality community in Beijing are quantified within the accounting framework proposed. Results show that emissions from supply chain emissions embodied in the consumption of goods cannot be ignored. Specific suggestions are also provided for the urban decision makers to achieve the optimal resource allocation and further promotion of low-carbon communities.

\section{Introduction}

Global warming has been a hot topic since a few decades ago and became a direct trigger for behavior change for people worldwide [1-35]. As the most impacted region by human activities, cities emit more than $75 \%$ of the total greenhouse gas, in which $\mathrm{CO}_{2}$ occupies a large proportion [36]. Cities play an important role in global carbon cycle, and most of their impacts are exerted via indirect pathways [37]. With the purpose of the energy resource consumption minimization and greenhouse gas emission reduction, lowcarbon cities have attracted increasing attention [38]. As the cell of a city, community is the basic unit in the low-carbon city construction, and its structure and density also play a key role in energy consumption and $\mathrm{CO}_{2}$ emission $[39,40]$. Low-carbon community provides a platform for individual behavior change $[41,42]$. The UK Low-Carbon Transition Plan [43] also makes explicit the major role that households and communities play in building a low-carbon future. A common viewpoint has been reached that low-carbon community will be an efficient way to achieve sustainable development due to its energy utilization, internal structure optimization, and external effects reduction. Obviously, the pursuit of low-carbon community would be extremely essential to retard the global climate change.

In order to estimate the contribution of cities to global climate change, many attempts have been made to quantify the carbon emissions associated with the accounting level in the community. Recently, many organizations have been conducting "low-carbon" projects to estimate the contributions to global climate change. Many protocols were put out to guide organizations to measure GHG emissions [4446]. These protocols are mainly concentrated on direct emissions and indirect emissions from purchased energy, with less focus on supply chain emissions that occupied a large proportion in a community. For example, direct $\mathrm{CO}_{2}$ emissions are found to be generated by direct household energy use, whereas indirect $\mathrm{CO}_{2}$ emissions are generated in the industrial sectors producing nonenergy commodities demanded by the households [47]. Pachauri and Spreng applied the IO models into the calculation of direct and indirect energy consumption of households in India based 
on the 115-sector classification input-output tables [48]. $\mathrm{Lu}$ et al. quantified the direct and indirect household emissions of $\mathrm{CO}_{2}$ in China with the help of input-output life-cycle assessment (IO-LCA) combined with 8 categories of household expenditure [49]. A calculation framework for whole life-circle carbon budget in residential area was presented based on building system, social system, and green space system, showing that the ratio of carbon source to carbon sink is $29: 1$ and that of society source to building source is $4.6: 1$ [50]. It can be seen that there is serious imbalance between carbon sink and carbon source in this residential area, and the society source is a key factor for carbon budget balance.

Moreover, Matthews et al. classified the variety scopes of carbon footprint into 3 tiers, including direct emissions, emissions from purchased energy, and supply chain emissions [51]. In their study, two case studies of book publishers and power generation were conducted, which illustrated that the first 2-tier emissions accounted for only a small part while a large portion is constituted by emissions embodied in the supply chain. The Scope 3 footprints of US economic sectors using a modified form of the 2002 US benchmark Economic Input-Output Life Cycle Assessment (EIO-LCA) model was developed to categorize upstream emission sources [52]. Larsen and Hertwich developed a greenhouse gas emissions inventory related to the provision of municipal services in the city of Trondheim, Norway, indicating that approximately 93\% of the total carbon footprint of municipal services is indirect emissions [53]. The authors also established $\mathrm{CO}_{2}$ inventories focused on the supply chain emissions of $\mathrm{CO}_{2}$ emissions from each sector, for example, agriculture, industry, transportation, and tertiary industry, and identified the sectors that contribute the most to climate change [54].

As can be seen, the previous studies on 3-tier accounting are mainly concentrated on industry sectors, with less focus on community-level $\mathrm{CO}_{2}$ emissions. A special focus should be transferred to identify Scope 3 categories that are relevant and incorporated into the footprint analysis. Thus, further characterization of the total supply chain emissions in community is necessary in order to achieve a better strategy for carbon emission mitigation. Approaches based on life cycle assessment (LCA) methods are available to estimate the embodied $\mathrm{CO}_{2}$ in the consumption of goods, which provides a framework for analysis of the potential environmental impacts embodied throughout the lifetime of goods $[55,56]$. There are two common types of LCA models, that is, process-based LCA and EIO-LCA, varying according to differences in system scope and analysis with its own processes and characteristics [57]. Economic IO models were first developed by Leontief in 1936 to aid manufacturing planning [58]. Compared to the process-based LCA, EIOLCA addresses some of the drawbacks of process-based LCA model and greatly expands the system scope to include the entire economy of a region, which can assess the energy consumption and environmental impacts of goods from a nationwide perspective based on economic input-output matrix.

The aim of this paper is to propose an efficient threetier carbon emission accounting framework for community.
Taking a typical high-quality community in Beijing as case study, this study also intends to quantify the magnitude of carbon emissions and the mitigation potential using the method of LCA in combination with a detailed $\mathrm{CO}_{2}$ emission inventory, including emissions from direct fossil fuel combustion, emissions from purchased energy (mainly contains electricity, water, and heat), and supply chain emissions embodied in the consumption of goods. Some suggestions about the realization of optimized resource allocation and further promotion of such communities are also given for the decision makers.

\section{Methodology}

We develop estimation equations for three tiers of carbon footprint of the community based on the scope initially developed by Matthews et al. [51].

Tier 1 includes direct emissions from household fossil fuel combustion and vehicles, including emissions from natural gas, gasoline, diesel oil, and jet kerosene. This is similar to the "consumer perspective" used for emissions inventories [59].

Tier 2 is based on Tier 1, in addition to indirect emissions from purchased energy (mainly contains electricity, water, and heat) for a community.

Tier 3 includes the total supply chain emissions embodied in the consumption of goods and activities. The accounting model and boundaries used for estimating all purchases and activities aspects in a supply chain by any sector of a community are based on EIO-LCA, which are consistent with the data structure described in Section 3.2.

The decomposition analysis is carried out in two steps. Firstly, Tier 1 and Tier $2 \mathrm{CO}_{2}$ emissions from household energy use are analyzed using a simple energy emission model. Secondly, Tier $3 \mathrm{CO}_{2}$ emissions are analyzed using an extended LCA model that also incorporates energy and emission matrices.

In terms of spatial system boundary, the total $\mathrm{CO}_{2}$ emissions are derived from emissions from household and public area. Thus the total $\mathrm{CO}_{2}$ emissions calculated in 3 tiers can be defined as

$$
\begin{gathered}
E=E_{h}+E_{p} \\
E_{h}=E_{h 1}+E_{h 2}+E_{h 3}+E_{h 4}+E_{h 5}+E_{h 6}+E_{h 7}+E_{h 8}+E_{h 9} \\
E_{p}=E_{p 1}+E_{p 2}
\end{gathered}
$$

where $E$ is the total $\mathrm{CO}_{2}$ emissions from community; $E_{h}$ refers to all the three-tiers $\mathrm{CO}_{2}$ emissions from household that consists of $\mathrm{CO}_{2}$ emissions from direct energy consumption $\left(E_{h 1}\right)$, indirect energy and water consumption $\left(E_{h 2}\right)$, transport and community $\left(E_{h 3}\right)$, food $\left(E_{h 4}\right)$, clothing and footwear $\left(E_{h 5}\right)$, household appliances and services $\left(E_{h 6}\right)$, healthcare $\left(E_{h 7}\right)$, education and recreation $\left(E_{h 8}\right)$, and from buildings $\left(E_{h 9}\right) ; E_{p}$ refers to $\mathrm{CO}_{2}$ emissions from the public area of a community that consisted of $\mathrm{CO}_{2}$ emissions from electricity consumption $\left(E_{p 1}\right)$ and from water consumption $\left(E_{p 2}\right)$. 
TABLE 1: The $\mathrm{CO}_{2}$ emissions factors of conventional energy.

\begin{tabular}{lcccc}
\hline & $\mathrm{Coal}\left(\mathrm{KgCO}_{2} / \mathrm{GJ}\right)$ & Natural gas $\left(\mathrm{KgCO}_{2} / \mathrm{GJ}\right)$ & Electricity $\left(\mathrm{KgCO}_{2} / \mathrm{kWh}\right)$ & $\mathrm{Gasoline}(\mathrm{KgCO} / \mathrm{GJ})$ \\
\hline $\mathrm{CO}_{2}$ emission coefficients & 110.08 & 56.10 & 1.15 & 69.30 \\
\hline
\end{tabular}

\section{Case Study}

3.1. Study Area. As Beijing is in its fast process of urbanization, community construction turns into a key element of the city renovation. This paper selects a typical high-quality community in Beijing as the case study. The community covers an area of $8.2 \times 10^{3} \mathrm{~m}^{2}$ with a construction area of $3.0 \times 10^{5} \mathrm{~m}^{2}$ and a living area of $9.0 \times 10^{4} \mathrm{~m}^{2}$. The community has 1630 households and a permanent population of 3100 , with a green space of more than $2500 \mathrm{~m}^{2}$ and a greening rate of $30 \%$. The community has carried out the garbage classification since 2004. So far, the capacity of the kitchen waste disposal equipment that came into use has reached $20 \mathrm{~kg}$ per day. The power consumption is $2.24 \times$ $10^{5} \mathrm{kWh}$ per month, and water consumption is about 1.63 $\times 10^{4} \mathrm{~m}^{3}$ per month.

3.2. Data Analysis. $\mathrm{CO}_{2}$ emission factors of primary energy are based on the $\mathrm{CO}_{2}$ content of the fuels and the type of energy, which are elaborated in IPCC [60]. $\mathrm{CO}_{2}$ emissions factors of electricity are based on coal factors but corrected by standard coal consumption of power supply (standard coal consumption $356 \mathrm{~g} / \mathrm{kWh}$, the average value in China [61]). $\mathrm{CO}_{2}$ emissions factors for renewable energy are considered to be zero. The $\mathrm{CO}_{2}$ emissions factors of energy are shown in Table 1. Other $\mathrm{CO}_{2}$ emission factors of consumption goods can be referred to the embodied greenhouse gas emission database [62].

In this study, direct $\mathrm{CO}_{2}$ emissions from the consumption of electricity and heating are not considered. The energy inputs for the production of electricity and district heating are estimated as the final consumption of energy production; that is, all emissions caused by energy production are specified for each of the fuel inputs [56].

The consumption data are developed based on the survey carried out in the community. Based on the previous studies engaged to classify the sectoral composition of consumption $[48,49,63]$, we aggregate the community consumption in the database into the same expenditure framework, of which 8 emission categories include food, clothing and footwear, household appliances and services, health care, transport and communication, education and recreation, building, and miscellaneous goods, as listed in Table 2.

\section{Results}

4.1. Comparison of Tier 1, Tier 2, and Tier $3 \mathrm{CO}_{2}$ Emissions. The results show that the first 2 tiers defined by the current most carbon footprint protocols only occupy a small fraction of the total supply chain (Tier 3). Direct emissions from the community are only $1.58 \%$ of the total emissions, and on average only $11.46 \%$ of Tier3 are captured by Tier 2 . The major carbon source is the total supply chain emissions

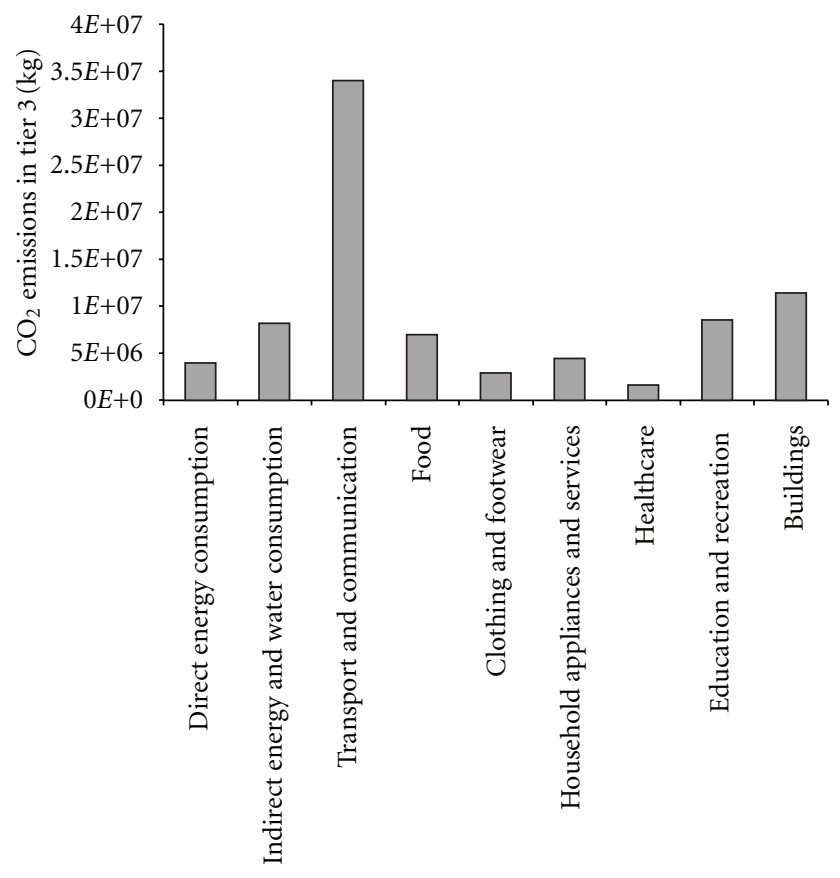

Figure 1: Total $\mathrm{CO}_{2}$ emissions in Tier 3.

embodied in the consumption of goods and activities, which is called Tier 3. Thus reduction emphasis should be put on Tier 3. From this aspect we can see that a large quantity of $\mathrm{CO}_{2}$ emissions may be underestimated according to the current estimation protocols.

4.2. $\mathrm{CO}_{2}$ Emissions Structure. For the total $\mathrm{CO}_{2}$ emissions, which are defined as Tier 3, the top 3 emission items are transport and communication $(41.36 \%)$, buildings $(14.11 \%)$, and education and recreation $(10.41 \%)$, as shown in Figure 1. Income is an important factor for $\mathrm{CO}_{2}$ emission. In a typical high-quality community of Beijing, residents enjoy a high-standard life and prefer more convenient and faster communication tools. Thus more private cars and advanced communication tools are needed, which add to the total emissions.

The buildings consume a large amount of materials, equipment, energy, and manpower at the stages of construction, fitment, outdoor facility construction, transportation, operation, waste treatment, property management, demolition, and disposal [64]. Due to a lack of data, only the main material consumption is considered in this study. Although this part occupies $14.11 \%$ of the total $\mathrm{CO}_{2}$ emission, it is still smaller than the real value.

Energy consumption tends to increase along with income rise, which is confirmed by numerous studies $[65,66]$. Thus, the main $\mathrm{CO}_{2}$ emissions are from goods purchasing. 
TABLE 2: Consumption categories of the community.

\begin{tabular}{lll}
\hline No. & Items & Contents \\
\hline 1 & Food & Miscellaneous food products, beverages, and tobacco products. \\
2 & Clothing and footwear & Miscellaneous textile products, leather footwear. \\
3 & Household appliances and services & $\begin{array}{l}\text { Electrical appliances (television, computer, and other electrical machinery). } \\
\text { Furniture and fixtures, wood products, and kitchen appliances. }\end{array}$ \\
4 & Healthcare & Cosmetics, medical and health services, and other services. \\
5 & Transport and communication & $\begin{array}{l}\text { Communication equipments, ships and boats, railway, motor vehicles, bicycles, } \\
\text { other transportation ways, and other transport services. }\end{array}$ \\
6 & Education and recreation & $\begin{array}{l}\text { Paper, paper products and newspapers, printing publishing and similar } \\
\text { activities, and education and research. }\end{array}$ \\
7 & Buildings & Residence and public buildings. \\
8 & Misc goods and service & Trade, banking, insurance, and so forth. \\
9 & Direct energy consumption & Natural gas, gasoline, diesel oil, and jet kerosene. \\
10 & Indirect energy and water consumption & Electricity, heat, and water.
\end{tabular}

The expenditure of health care is the smallest, which is mainly due to the age structure present in this community.

4.3. Comparison with Nanjing Community. There is a previous study on the typical community of Nanjing-Zhujiang Road Community (termed as Site A) [67]. Per capita $\mathrm{CO}_{2}$ emissions of Site A from electricity, natural gas, and petrol consumptions are $1144.5 \mathrm{~kg}, 48.7 \mathrm{~kg}$, and $540.1 \mathrm{~kg}$, while in our case are $974.19 \mathrm{~kg}, 374.19 \mathrm{~kg}$, and $893.55 \mathrm{~kg}$, respectively. $\mathrm{CO}_{2}$ emission from electricity of Beijing case is $14.88 \%$ lower than that of Site A. The younger residents in Beijing community have a better sense of energy conservation and usually prefer energy saving appliances. The $\mathrm{CO}_{2}$ emission from natural gas of Beijing case is nearly seven times higher than that of Site A because space heating in northern China contributes the most while people do not have heating services in southern China like Nanjing. Meanwhile, the $\mathrm{CO}_{2}$ emissions from petrol consumption of Beijing case are $65.44 \%$ higher than that of Site A due to longer distance between working place and home in Beijing compared to Nanjing. Particularly, our case considers the total emissions embodied in the supply chain, which is often significantly underestimated by the previous studies.

\section{Conclusions}

In this paper, a new carbon accounting framework, that is, three-tier accounting method, was established to estimate the total embodied $\mathrm{CO}_{2}$ emissions of urban community. The carbon emissions and the mitigation potential were quantified according to the proposed accounting framework. From the results we can obtain that in the concerned community only $11.46 \%$ of Tier 3 are captured by Tier 2 . The major carbon source is the total supply chain emissions embodied in the consumption of goods and activities. The results also indicated that for the total $\mathrm{CO}_{2}$ emissions, the top 3 emission items are transport and communication (41.36\%), buildings $(14.11 \%)$, and education and recreation $(10.41 \%)$.
As can be seen, the mitigation emphases should be placed on Tier 3. Two major suggestions are thereby provided to realize the optimal resource allocation and further promotion for such communities. One is that we should strengthen the promotion of energy-efficient or green building and pay more attention to the renewable energy appliances such as solar energy water heater. The architectural of the houses should also be improved to reduce energy consumption of lightning and space heating. On the other hand, due to public transportation, the reconstruction of the urban public transportation is needed to reduce $\mathrm{CO}_{2}$ emissions caused by the huge growth of private car ownership.

\section{Acknowledgments}

This study was supported by the Key Program of National Natural Science Foundation (no. 50939001), National Science Foundation for Innovative Research Group (no. 51121003), National Natural Science Foundation (no. 41271543), and Program for New Century Excellent Talents in University (NCET-09-0226). The authors are especially grateful for the financial support from Beijing Development Area Co. Ltd.

\section{References}

[1] S. Q. Chen, B. Chen, and D. Song, "Life-cycle energy production and emissions mitigation by comprehensive biogasdigestate utilization," Bioresource Technology, vol. 114, pp. 357-364, 2012.

[2] J. Wang, M. R. Su, B. Chen, S. Q. Chen, and C. Liang, "A comparative study of Beijing and three global cities: a perspective on urban livability," Frontiers of Earth Science in China, vol. 5, no. 3, pp. 323-329, 2011.

[3] B. Chen, G. Q. Chen, and Z. F. Yang, "Exergy-based resource accounting for China," Ecological Modelling, vol. 196, no. 3-4, pp. 313-328, 2006.

[4] B. Chen and G. Q. Chen, "Ecological footprint accounting based on emergy-a case study of the Chinese society," Ecological Modelling, vol. 198, no. 1-2, pp. 101-114, 2006. 
[5] B. Chen, G. Q. Chen, Z. F. Yang, and M. M. Jiang, "Ecological footprint accounting for energy and resource in China," Energy Policy, vol. 35, no. 3, pp. 1599-1609, 2007.

[6] G. Q. Chen and B. Chen, "Resource analysis of the Chinese society 1980-2002 based on exergy_part 1: fossil fuels and energy minerals," Energy Policy, vol. 35, no. 4, pp. 2038-2050, 2007.

[7] B. Chen and G. Q. Chen, "Resource analysis of the Chinese society 1980 -2002 based on exergy_-part 2: renewable energy sources and forest," Energy Policy, vol. 35, no. 4, pp. 20512064, 2007.

[8] B. Chen and G. Q. Chen, "Resource analysis of the Chinese society 1980-2002 based on exergy-part 3: agricultural products," Energy Policy, vol. 35, no. 4, pp. 2065-2078, 2007.

[9] B. Chen and G. Q. Chen, "Resource analysis of the Chinese society 1980-2002 based on exergy-part 4: fishery and rangeland," Energy Policy, vol. 35, no. 4, pp. 2079-2086, 2007.

[10] B. Chen and G. Q. Chen, "Resource analysis of the Chinese society 1980-2002 based on energy-part 5: resource structure and intensity," Energy Policy, vol. 35, no. 4, pp. 2087-2095, 2007.

[11] Z. M. Chen, B. Chen, J. B. Zhou et al., "A vertical subsurfaceflow constructed wetland in Beijing," Communications in Nonlinear Science and Numerical Simulation, vol. 13, no. 9, pp. 1986-1997, 2008.

[12] X. H. Zhang, H. W. Zhang, B. Chen, G. Q. Chen, and X. H. Zhao, "Water resources planning based on complex system dynamics: a case study of Tianjin city," Communications in Nonlinear Science and Numerical Simulation, vol. 13, no. 10, pp. 2328-2336, 2008.

[13] M. M. Jiang, J. B. Zhou, B. Chen, and G. Q. Chen, "Emergybased ecological account for the Chinese economy in 2004," Communications in Nonlinear Science and Numerical Simulation, vol. 13, no. 10, pp. 2337-2356, 2008.

[14] B. Chen, Z. M. Chen, Y. Zhou, J. B. Zhou, and G. Q. Chen, "Emergy as embodied energy based assessment for local sustainability of a constructed wetland in Beijing," Communications in Nonlinear Science and Numerical Simulation, vol. 14, no. 2, pp. 622-635, 2009.

[15] B. Chen, G. Q. Chen, F. H. Hao, and Z. F. Yang, "The water resources assessment based on resource exergy for the mainstream Yellow River," Communications in Nonlinear Science and Numerical Simulation, vol. 14, no. 1, pp. 331-344, 2009.

[16] B. Chen and G. Q. Chen, "Emergy-based energy and material metabolism of the Yellow River basin," Communications in Nonlinear Science and Numerical Simulation, vol. 14, no. 3, pp. 923-934, 2009.

[17] X. M. Wei, B. Chen, Y. H. Qu, C. Lin, and G. Q. Chen, "Emergy analysis for "Four in One" peach production system in Beijing," Communications in Nonlinear Science and Numerical Simulation, vol. 14, no. 3, pp. 946-958, 2009.

[18] B. Chen, G. Q. Chen, F. H. Hao, and Z. F. Yang, "Exergybased water resource allocation of the mainstream Yellow River," Communications in Nonlinear Science and Numerical Simulation, vol. 14, no. 4, pp. 1721-1728, 2009.

[19] Q. Yang, B. Chen, X. Ji, Y. F. He, and G. Q. Chen, "Exergetic evaluation of corn-ethanol production in China," Communications in Nonlinear Science and Numerical Simulation, vol. 14, no. 5, pp. 2450-2461, 2009.

[20] J. B. Zhou, M. M. Jiang, B. Chen, and G. Q. Chen, "Emergy evaluations for constructed wetland and conventional wastewater treatments," Communications in Nonlinear Science and Numerical Simulation, vol. 14, no. 4, pp. 1781-1789, 2009.
[21] G. Y. Liu, Z. F. Yang, B. Chen et al., "Emergy-based urban ecosystem health assessment: a case study of Baotou, China," Communications in Nonlinear Science and Numerical Simulation, vol. 14, no. 3, pp. 972-981, 2009.

[22] M. R. Su, Z. F. Yang, and B. Chen, "Set pair analysis for urban ecosystem health assessment," Communications in Nonlinear Science and Numerical Simulation, vol. 14, no. 4, pp. 17731780, 2009.

[23] Y. Zhang, Y. W. Zhao, Z. F. Yang, B. Chen, and G. Q. Chen, "Measurement and evaluation of the metabolic capacity of an urban ecosystem," Communications in Nonlinear Science and Numerical Simulation, vol. 14, no. 4, pp. 1758-1765, 2009.

[24] L. X. Zhang, B. Chen, Z. F. Yang, G. Q. Chen, M. M. Jiang, and G. Y. Liu, "Comparison of typical mega cities in China using emergy synthesis," Communications in Nonlinear Science and Numerical Simulation, vol. 14, no. 6, pp. 2827-2836, 2009.

[25] M. M. Jiang, J. B. Zhou, B. Chen et al., "Ecological evaluation of Beijing economy based on emergy indices," Communications in Nonlinear Science and Numerical Simulation, vol. 14, no. 5, pp. 2482-2494, 2009.

[26] Z. F. Yang, T. Sun, B. S. Cui, B. Chen, and G. Q. Chen, "Environmental flow requirements for integrated water resources allocation in the Yellow River Basin, China," Communications in Nonlinear Science and Numerical Simulation, vol. 14, no. 5, pp. 2469-2481, 2009.

[27] X. Zhao, B. Chen, and Z. F. Yang, "National water footprint in an input-output framework- a case study of China 2002," Ecological Modelling, vol. 220, no. 2, pp. 245-253, 2009.

[28] G. Q. Chen, M. M. Jiang, J. B. Zhou, B. Chen, Z. F. Yang, and X. Ji, "Exergetic assessment for ecological economic system: Chinese agriculture," Ecological Modelling, vol. 220, no. 3, pp. 397-410, 2009.

[29] Z. F. Cai, Q. Yang, B. Zhang, H. Chen, B. Chen, and G. Q. Chen, "Water resources in unified accounting for natural resources," Communications in Nonlinear Science and Numerical Simulation, vol. 14, no. 9-10, pp. 3693-3704, 2009.

[30] X. Ji, G. Q. Chen, B. Chen, and M. M. Jiang, "Exergybased assessment for waste gas emissions from Chinese transportation," Energy Policy, vol. 37, no. 6, pp. 2231-2240, 2009.

[31] G. Q. Chen and B. Chen, "Extended-exergy analysis of the Chinese society," Energy, vol. 34, no. 9, pp. 1127-1144, 2009.

[32] M. R. Su, Z. F. Yang, B. Chen, and S. Ulgiati, "Urban ecosystem health assessment based on emergy and set pair analysisa comparative study of typical Chinese cities," Ecological Modelling, vol. 220, no. 18, pp. 2341-2348, 2009.

[33] G. Y. Liu, Z. F. Yang, B. Chen, and S. Ulgiati, "Emergy-based urban health evaluation and development pattern analysis," Ecological Modelling, vol. 220, no. 18, pp. 2291-2301, 2009.

[34] Z. F. Yang, M. M. Jiang, B. Chen, J. B. Zhou, G. Q. Chen, and S. C. Li, "Solar emergy evaluation for Chinese economy," Energy Policy, vol. 38, no. 2, pp. 875-886, 2010.

[35] Z. M. Chen, G. Q. Chen, J. B. Zhou, M. M. Jiang, and B. Chen, "Ecological input-output modeling for embodied resources and emissions in Chinese economy 2005," Communications in Nonlinear Science and Numerical Simulation, vol. 15, no. 7, pp. 1942-1965, 2010.

[36] IPCC, “Climate change 2007,” Comprehensive Report, 2007.

[37] S. Q. Chen and B. Chen, "Network environ perspective for urban metabolism and carbon emissions: a case study of Vienna, Austria," Environmental Science and Technology, vol. 46, no. 8, pp. 4498-4506, 2012. 
[38] Y. X. Dai, "The necessity and governance model of developing low carbon city in China," China Population, Resources and Environment, vol. 19, no. 3, pp. 12-17, 2009 (Chinese).

[39] Z. P. Xin and Y. T. Zhang, "Low carbon community and its practice," Urban Issues, no. 10, pp. 91-95, 2008 (Chinese).

[40] ARUP, "Beijing changxindian low carbon community concept plan," Urbanism and Architecture, no. 2, pp. 44-46, 2010 (Chinese).

[41] L. Middlemiss, "Influencing individual sustainability: a review of the evidence on the role of community-based organisations," International Journal of Environment and Sustainable Development, vol. 7, no. 1, pp. 78-93, 2008.

[42] E. Heiskanen, M. Johnson, S. Robinson, E. Vadovics, and M. Saastamoinen, "Low-carbon communities as a context for individual behavioural change," Energy Policy, vol. 38, no. 12, pp. 7586-7595, 2010.

[43] Department of Energy and Climate Change (DECC), Low Carbon Transition Plan, Department of Energy and Climate Change (DECC), London, UK, 2009.

[44] INC/FCCC, United Nations Framework Convention on Climate Change, 2000.

[45] EPD and EMSD, Guidelines to Account for and Report on Greenhouse Gas Emissions and Removals for Buildings in Hong Kong, 2008.

[46] CBEEX, Panda Standard, 2009.

[47] J. Munksgaard, K. A. Pedersen, and M. Wien, "Impact of household consumption on $\mathrm{CO}_{2}$ emissions," Energy Economics, vol. 22, no. 4, pp. 423-440, 2000.

[48] S. Pachauri and D. Spreng, "Direct and indirect energy requirements of households in India," Energy Policy, vol. 30, no. 6, pp. 511-523, 2002.

[49] Z. Lu, R. Matsuhashi, and Y. Yoshida, "Direct and indirect impacts of households by region of China on $\mathrm{CO}_{2}$ emissions," Environmental Informatics Archives, vol. 5, pp. 214-223, 2007.

[50] H. He, "Research on green space carbon sink of residential area in South China and its application in carbon budget of residential area for whole life circle" (Chinese), 12, Chongqing University, 2010.

[51] H. S. Matthews, C. T. Hendrickson, and C. L. Weber, "The importance of carbon footprint estimation boundaries," Environmental Science and Technology, vol. 42, no. 16, pp. 5839-5842, 2008.

[52] Y. A. Huang, C. L. Weber, and H. S. Matthews, "Categorization of scope 3 emissions for streamlined enterprise carbon footprinting," Environmental Science and Technology, vol. 43, no. 22, pp. 8509-8515, 2009.

[53] H. N. Larsen and E. G. Hertwich, "The case for consumptionbased accounting of greenhouse gas emissions to promote local climate action," Environmental Science and Policy, vol. 12, no. 7, pp. 791-798, 2009.

[54] L. P. Ju and B. Chen, "An input-output model to analyze sector linkages and $\mathrm{CO}_{2}$ emissions," Procedia Environmental Sciences, vol. 2, pp. 1841-1845, 2010.

[55] A. Tukker, "Life cycle assessment as a tool in environmental impact assessment," Environmental Impact Assessment Review, vol. 20, no. 4, pp. 435-456, 2000.

[56] EN ISO 14040, "Environmental management-life cycle assessment—principles and framework," 2006.

[57] Y. Chang, R. J. Ries, and Y. W. Wang, "The embodied energy and environmental emissions of construction projects in China: an economic input-output LCA model," Energy Policy, vol. 38 , no. 11 , pp. 6597-6603, 2010.
[58] W. W. Leontief, "Quantitative input and output relations in the economic systems of the United States," Review of Economics and Statistics, vol. 18, no. 3, pp. 105-125, 1936.

[59] J. Munksgaard and K. A. Pedersen, " $\mathrm{CO}_{2}$ accounts for open economies: producer or consumer responsibility?" Energy Policy, vol. 29, no. 4, pp. 327-334, 2001.

[60] IPCC National Greenhouse Gas Inventories Programme, 2006 IPCC Guidelines For National Greenhouse Gas Inventories, vol. 2 of Energy, Institute for Global Environmental Strategies, Hayama, Japan, 2006.

[61] Chinese Academy for Environment Planning, Analysis and Forecast of Environment and Economic about the Key Industries of Energy Saving and Emission Reduction in China From 20092020, China Environmental Science Press, Beijing, China, 2009.

[62] G. Q. Chen, "Systems cart on metrics for building” (Chinese), Beijing, China, 2010.

[63] C. L. Weber and H. S. Matthews, "Quantifying the global and distributional aspects of American household carbon footprint," Ecological Economics, vol. 66, no. 2-3, pp. 379-391, 2008.

[64] G. Q. Chen, H. Chen, Z. M. Chen et al., "Low-carbon building assessment and multi-scale input-output analysis," Communications in Nonlinear Science and Numerical Simulation, vol. 16, no. 1, pp. 583-595, 2011.

[65] L. D. Shorrock, "Identifying the individual components of United Kingdom domestic sector carbon emission changes between 1990 and 2000," Energy Policy, vol. 28, no. 3, pp. 193200, 2000 .

[66] L. J. Schipper, R. Haas, and C. Sheinbaum, "Recent trends in residential energy use in OECD countries and their impact on carbon dioxide emissions: A comparative analysis of the period 1973-1992," Mitigation and Adaptation Strategies for Global Change, vol. 1, no. 2, pp. 167-196, 1996.

[67] Z. H. Gu, Q. Sun, and R. Wennersten, "Impact of urban residences on energy consumption and carbon emissions-an investigation in Nanjing," China, 2012. 

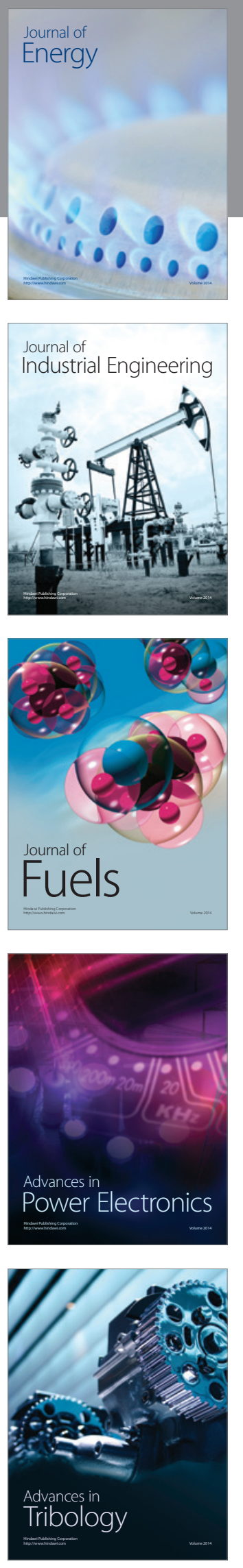
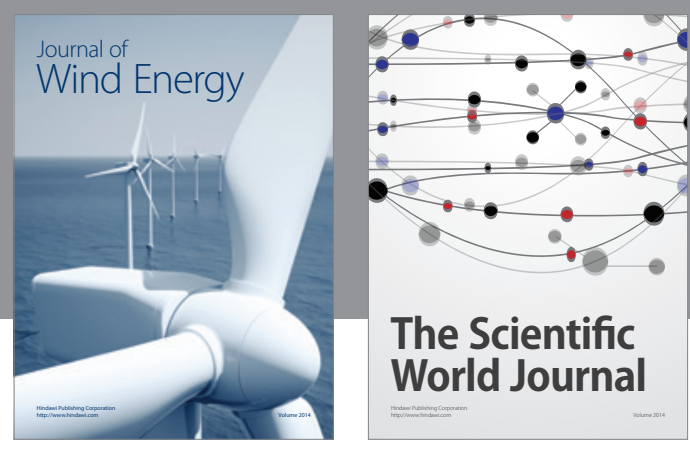

The Scientific World Journal

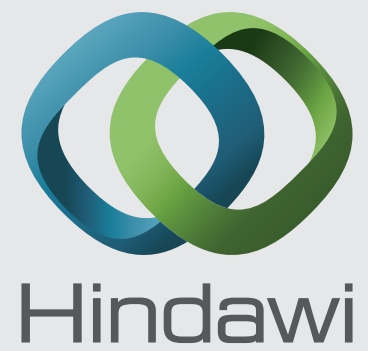

Submit your manuscripts at http://www.hindawi.com
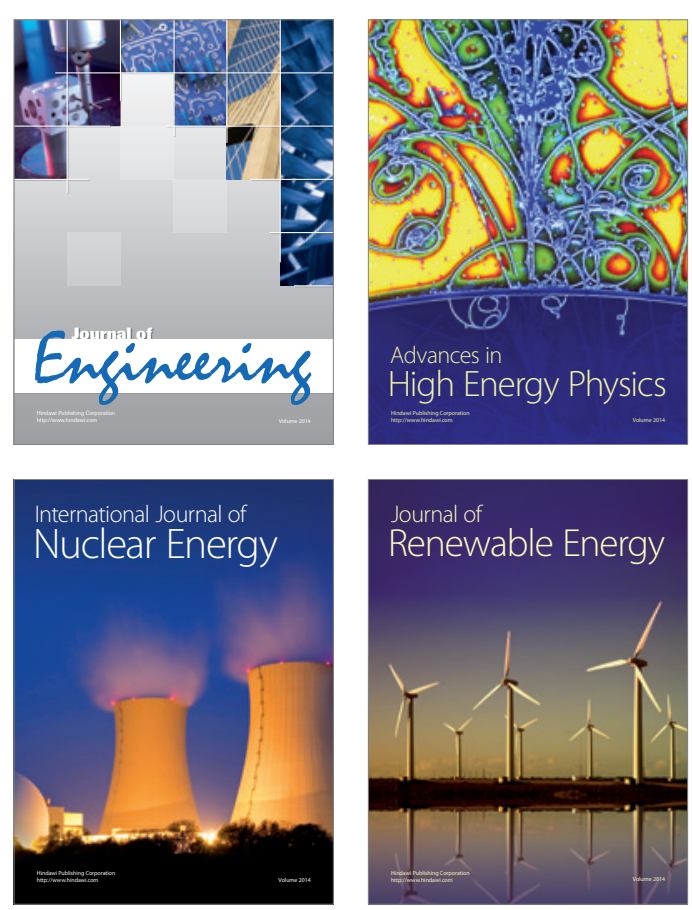

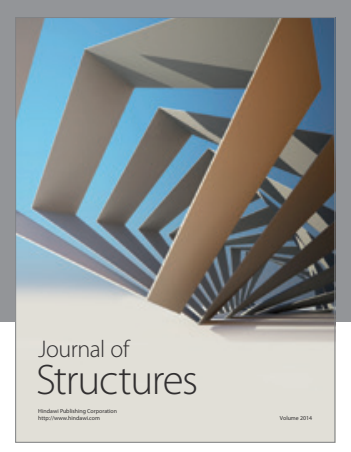

Rotating
Mechinery
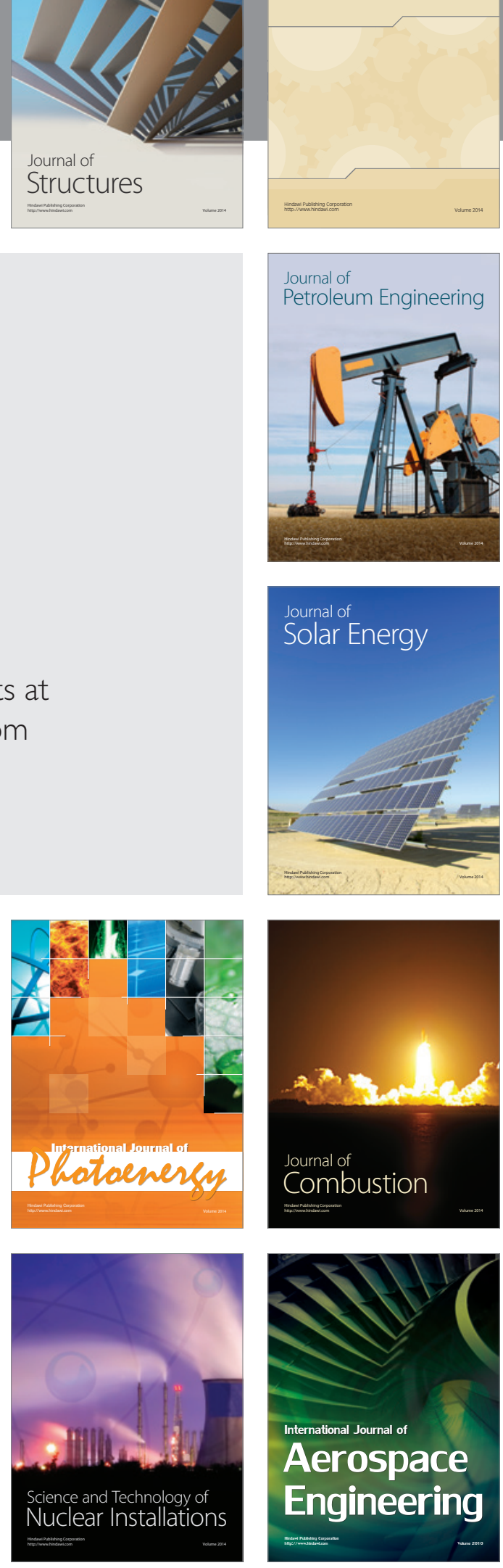